\title{
Enhanced oral delivery of insulin via the colon-targeted nanocomposite system of organoclay/glycol chitosan/Eudragit ${ }^{\circledR}$ S100
}

\author{
Sang Hoon Lee, Seung-Yun Back, Jae Geun Song and Hyo-Kyung Han*
}

\begin{abstract}
This study aimed to develop a ternary nanocomposite system of organoclay, glycol-chitosan, and Eudragit ${ }^{\circledR}$ S100 as an effective colon targeted drug delivery carrier to enhance the oral absorption of insulin. A nanocomplex of insulin and aminoclay was prepared via spontaneous co-assembly, which was then coated with glycol-chitosan and Eudragit $S^{\circledR} 100$ (EGAC-Ins). The double coated nanocomplex, EGAC-Ins demonstrated a high entrapment efficiency of greater than $90 \%$ and a pH-dependent drug release. The conformational stability of insulin entrapped in EGAC-Ins was effectively maintained in the presence of proteolytic enzymes. When compared to a free insulin solution, EGACIns enhanced drug permeability by approximately sevenfold in Caco-2 cells and enhanced colonic drug absorption in rats. Accordingly, oral EGAC-Ins significantly reduced blood glucose levels in diabetic rats while the hypoglycemic effect of an oral insulin solution was negligible. In conclusion, EGAC-Ins should be a promising colonic delivery system for improving the oral absorption of insulin.
\end{abstract}

Keywords: Insulin, Oral delivery system, Colon targeting, Nano-carrier, Aminoclay

\section{Introduction}

Protein-based drugs cover diverse therapeutic indications and are beneficial in the treatment of many incurable diseases [1]. Particularly, the high target-selectivity of protein drugs can reduce undesirable side effects and toxicity [2]. Thus, a large amount of research and development has been devoted to biological drugs including proteins and peptides. In current medical practice, protein drugs are primarily administered via parenteral injection because of their low bioavailability [3]. Therefore, there is a high demand for the non-invasive formulations of protein drugs that can improve patient compliance.

Diabetes mellitus (DM) is a chronic metabolic disease that is present in a large portion of the patient population (i.e. more than 415 million adults), and it is predicted to reach 642 million patients by 2040 [4]. DM is classified

*Correspondence: hkhan@dongguk.edu

College of Pharmacy, Dongguk University-Seoul, Dongguk-ro-32,

Ilsan-Donggu, Goyang, Korea into two main types: type 1 and type 2 [5]. Type $1 \mathrm{DM}$ is caused by autoimmune reactions of beta cells in pancreatic islets [6]. Type $2 \mathrm{DM}$ is caused by either malfunctioning or defective pancreatic beta cell that lead to reduced insulin signaling and secretion from the pancreas. Insulin is used to treat type $1 \mathrm{DM}$ patients that exhibit insulin deficiency as well as type 2 patients at a later stage when adequate glycemic control is not achievable by diet, regular exercise, weight loss, or oral anti-diabetic agents [7, 8]. Since high blood glucose levels can damage tissues and cause severe complications including blindness, cardiovascular diseases, and non-traumatic amputation [4], effective insulin administration is important in the treatment of DM.

Insulin is primarily administered via subcutaneous (SC) injections [9]; however, injectable formulations can have drawbacks that include pain, immune reactions, infections, hypoglycemia, and the discomfort of longterm therapy $[4,9]$. As a result, many researchers have tried to develop non-invasive insulin formulations via the 
alternative routes of administration such as oral, nasal, ocular, and transdermal. Oral administration is the most preferred route of administration because it is cost-effective, safe, and pain-free [4]. However, the oral delivery of insulin has many obstacles including physicochemical instability in the gastrointestinal tract, low intestinal permeability due to high molecular mass and hydrophilicity, and extensive enzymatic degradation that lead to extremely low oral bioavailability and ineffectiveness in controlling blood glucose level [10-12]. Therefore, many formulation approaches have attempted to improve the intestinal absorption as well as the physicochemical and enzymatic stability of orally administered insulin, which are exemplified by M-cell targeted- or colon-targeted delivery systems and cell-penetrating protein (CPP)-conjugated nanoparticles [13]. Particularly, colon-targeted protein drug delivery systems have been actively pursued because the colon has low proteolytic activity, has a neutral $\mathrm{pH}$, is highly responsive to absorption enhancers, and allows for longer residence time $[14,15]$.

Aminoclay (3-aminopropyl functionalized magnesium phyllosilicate) is a nontoxic, silicate-based material that is positively charged in water $[16,17]$. In addition, aminoclay has a high adsorption capacity $[17,18]$. Glycolchitosan is biocompatible and biodegradable, has low immunogenicity, and exhibits good aqueous solubility in all $\mathrm{pH}$ ranges [19-22]. Glycol-chitosan can retain its positive charge in the small intestine, which may enhance its retention in the GI tract via electrostatic interactions with negatively charged intestinal membranes [23, 24]. Since the solubility of Eudragit ${ }^{\circledR}$ S100 is pH-dependent (i.e. it dissolves at pHs greater than 7.0) $[9,25,26]$, an Eudragit ${ }^{\circledR}$ S100 surface coating can prevent drug release in the stomach and upper intestine [27]. Therefore, the present study involved the construction of an insulin colonic delivery system comprised of an insulin and aminoclay nanocomplex coated with glycol-chitosan and Eudragit ${ }^{\circledR}$ S100. The structural and in vitro characteristics of the developed nanoparticles were evaluated, and the in vivo effectiveness was assessed in diabetic rats.

\section{Results and discussion}

\section{Structural characterization of nanoparticles}

As summarized in Table 1, all nanoparticles had a narrow size distribution and a high entrapment efficiency greater than $90 \%$. Insulin-aminoclay nanocomplex (AC-Ins), prepared via electrostatic interactions, was $192 \pm 8.20 \mathrm{~nm}$ in size and had a zeta-potential of $-14.0 \pm 4.4 \mathrm{mV}$. The sequential coating of AC-Ins with glycol-chitosan and Eudragit ${ }^{\circledR}$ S100 increased the size of the nanoparticles and reversed their surface charge (particle size and zetapotential were $319 \pm 9.42 \mathrm{~nm}$ and $15.6 \pm 2.31 \mathrm{mV}$ for
Table 1 Characteristics of nanocomposite formulations (Mean \pm SD, $\mathbf{n}=3$ )

\begin{tabular}{|c|c|c|c|c|}
\hline Formulation & Size (nm) & PDI & $\begin{array}{l}\text { Zeta-potential } \\
(\mathrm{mV})\end{array}$ & EE (\%) \\
\hline$A C-\operatorname{Ins}$ & $192 \pm 8.20$ & $0.20 \pm 0.01$ & $-14.0 \pm 4.41$ & $97.6 \pm 1.20$ \\
\hline GAC-Ins & $319 \pm 9.42$ & $0.46 \pm 0.02$ & $15.6 \pm 2.31$ & $90.7 \pm 3.14$ \\
\hline EGAC-Ins & $412 \pm 10.4$ & $0.32 \pm 0.02$ & $-20.6 \pm 0.76$ & $90.3 \pm 1.06$ \\
\hline
\end{tabular}

GAC-Ins and $412 \pm 10.4 \mathrm{~nm}$ and $-20.6 \pm 0.76 \mathrm{mV}$ for EGAC-Ins).

The formation of AC-Ins was confirmed by FT-IR analysis. As shown in Fig. 1a, the FT-IR spectrum of aminoclay indicated the absorption bands of $\mathrm{N}-\mathrm{H}\left(1608 \mathrm{~cm}^{-1}\right.$, $\left.1502 \mathrm{~cm}^{-1}\right)$, Si-O-Si $\left(995 \mathrm{~cm}^{-1}\right)$, and $\mathrm{Mg}-\mathrm{O}\left(550 \mathrm{~cm}^{-1}\right)$ [16]. The FT-IR spectrum of insulin exhibited amide I peak at $1645 \mathrm{~cm}^{-1}$ and amide II peak at $1515 \mathrm{~cm}^{-1}$. The FT-IR spectrum of AC-Ins exhibited absorption bands from both insulin and aminoclay such as peaks at $1514 \mathrm{~cm}^{-1}$ and $1644 \mathrm{~cm}^{-1}$ from the amide bonds of insulin and at $1009 \mathrm{~cm}^{-1}$ and $550 \mathrm{~cm}^{-1}$ from aminoclay [28], suggesting the formation of an insulin and aminoclay complex. Furthermore, EDX analysis of EGAC-Ins indicated the elemental composition originating from aminoclay ( $\mathrm{Si}, \mathrm{Mg}$ ) and insulin (S), confirming the integration of insulin and aminoclay into the nanoparticles (Fig. 1b). The morphology of the nanoparticles was also examined by TEM. As shown in Fig. 1c, the nanoparticles had spherical shapes and their size was comparable to the size determined by dynamic light scattering.

Since the structural stabilization of proteins is critical in the formulation development process of protein drugs [29], the conformational stability of insulin entrapped in the nanoparticles was evaluated by CD spectroscopy and compared with native insulin. As shown in Fig. 1d, the CD spectra of insulin released from the nanoparticles were similar to that of native insulin, indicating that the conformational structure of insulin was preserved in the nanoparticles.

\section{In vitro drug release studies}

Drug release profiles of the nanoparticles were examined in a $\mathrm{pH}$ range of 1.2-7.4 to reflect intestinal $\mathrm{pH}$ conditions. As summarized in Fig. 2, AC-Ins exhibited rapid drug release between acidic to neutral $\mathrm{pHs}$, and it released $60-70 \%$ of the drug within $15 \mathrm{~min}$ at $\mathrm{pH} 1.2$. In contrast, EGAC-Ins showed minimal drug release $(<10 \%)$ at $\mathrm{pH} 1.2$ and $\mathrm{pH} 6.8$ because the outer coating layer of Eudragit ${ }^{\circledR} \mathrm{S} 100$ is insoluble at $\mathrm{pH}$ less than 7.0. Since Eudragit ${ }^{\circledR} \mathrm{S} 100$ has carboxyl groups that ionize when the $\mathrm{pH}$ changes from acidic to alkaline, the outer coat of Eudragit ${ }^{\circledR}$ S100 dissolves at pH 7.4 [9, $25,26,30]$. Accordingly, drug release from EGAC-Ins 

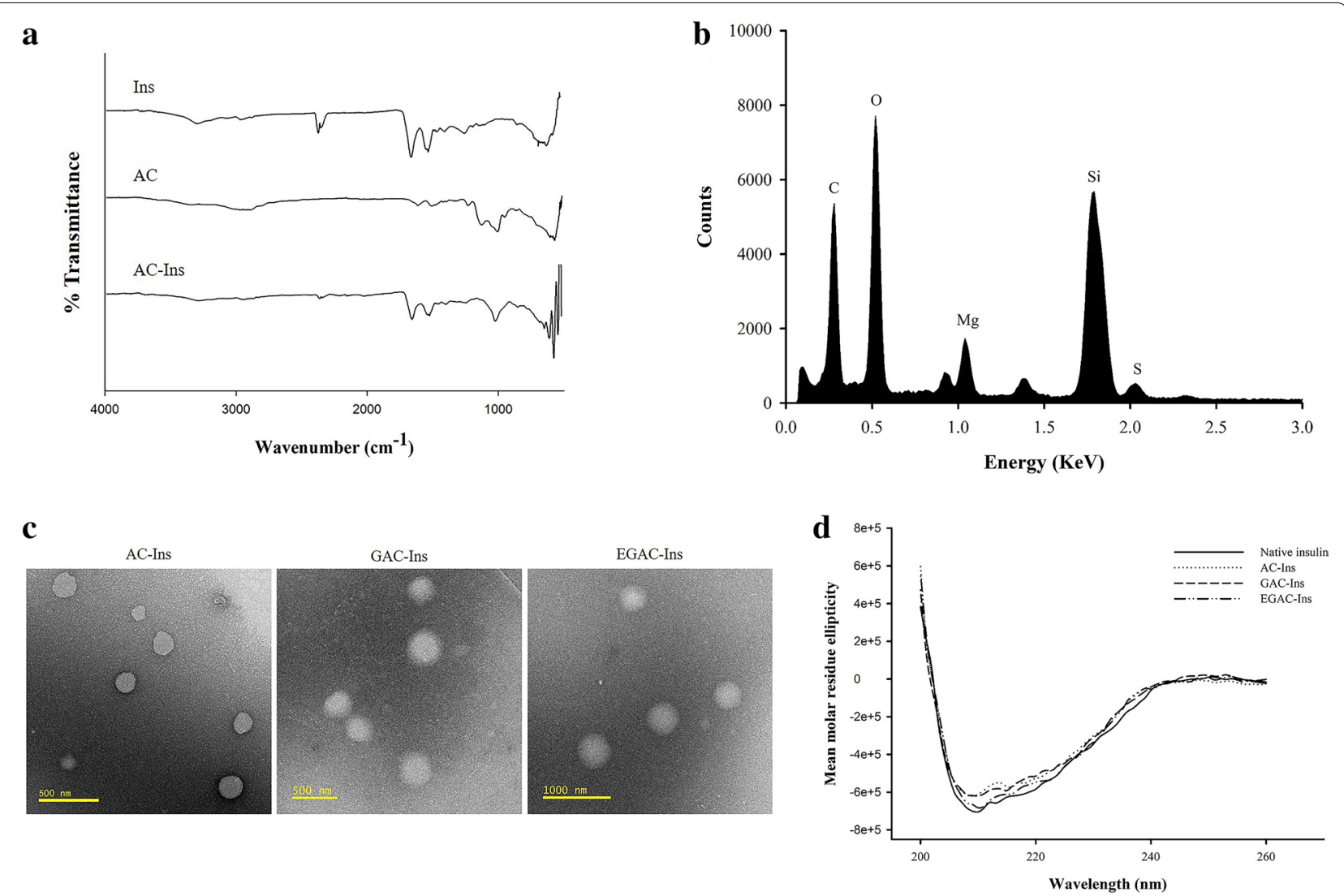

Fig. 1 In vitro characterization of formulations. FT-IR spectra (a), EDX spectrum of EGAC-Ins (b), TEM images (c) (scale bar: $500 \mathrm{~nm}$ for AC-Ins and GAC-Ins, $1000 \mathrm{~nm}$ for EGAC-Ins), and CD spectra of insulin released from the nanoparticles (d)

increased up to $40 \%$ at $\mathrm{pH} 7.4$ and was similar to those from AC-Ins and GAC-Ins (Fig. 2). The pH-dependent drug release characteristics of EGAC-Ins could be beneficial because they can protect insulin from the acidic environment of the stomach and release it in the large intestine.

\section{Protection against enzymatic degradation}

Protein drugs are susceptible to gastrointestinal (GI) destabilization by the acidic gastric fluids and proteolytic enzymes in the GI tract. This is a major barrier to oral protein delivery [31, 32]. Therefore, the protective effect of the nanoparticles against the gastrointestinal destabilization of insulin was examined by using simulated gastrointestinal fluids containing proteolytic enzymes. After incubating each formulation in SGF or SIF, the structural stability of insulin entrapped in the nanoparticles was evaluated by $\mathrm{CD}$ spectroscopy. As summarized in Fig. 3, insulin entrapped in AC-Ins and GAC-Ins was completely degraded in SGF. In contrast, insulin in EGAC-Ins retained its conformational stability in both SGF and SIF. These results suggest that EGAC-Ins are effective at protecting insulin against gastrointestinal destabilization.

\section{Cellular transport studies}

Before the cellular uptake and transport studies, the cytotoxicity of the developed nanoparticles was evaluated via MTT studies. None of the nanoparticles were cytotoxic in Caco-2 cells up to a $100 \mu \mathrm{M}$ drug concentration (data not shown).

The cellular uptake of nanoparticles containing fluorescent labelled-insulin (FITC-Ins) was evaluated in Caco-2 cells. As illustrated in Fig. 4, a bio-imaging assay using CLSM showed the effective intracellular distribution of FITC-Ins by the nanocomposite formulations. After incubating cells with the nanoparticles, strong fluorescence intensity of FITC-Ins was observed in the cytoplasm around the DAPI-stained nuclei. This implies that the nanoparticles were effective at enhancing the intracellular uptake of insulin. In parallel, the apical to basolateral permeability $\left(\mathrm{P}_{\text {app }}\right)$ of insulin using different formulations was also determined in Caco-2 cells. Compared to 


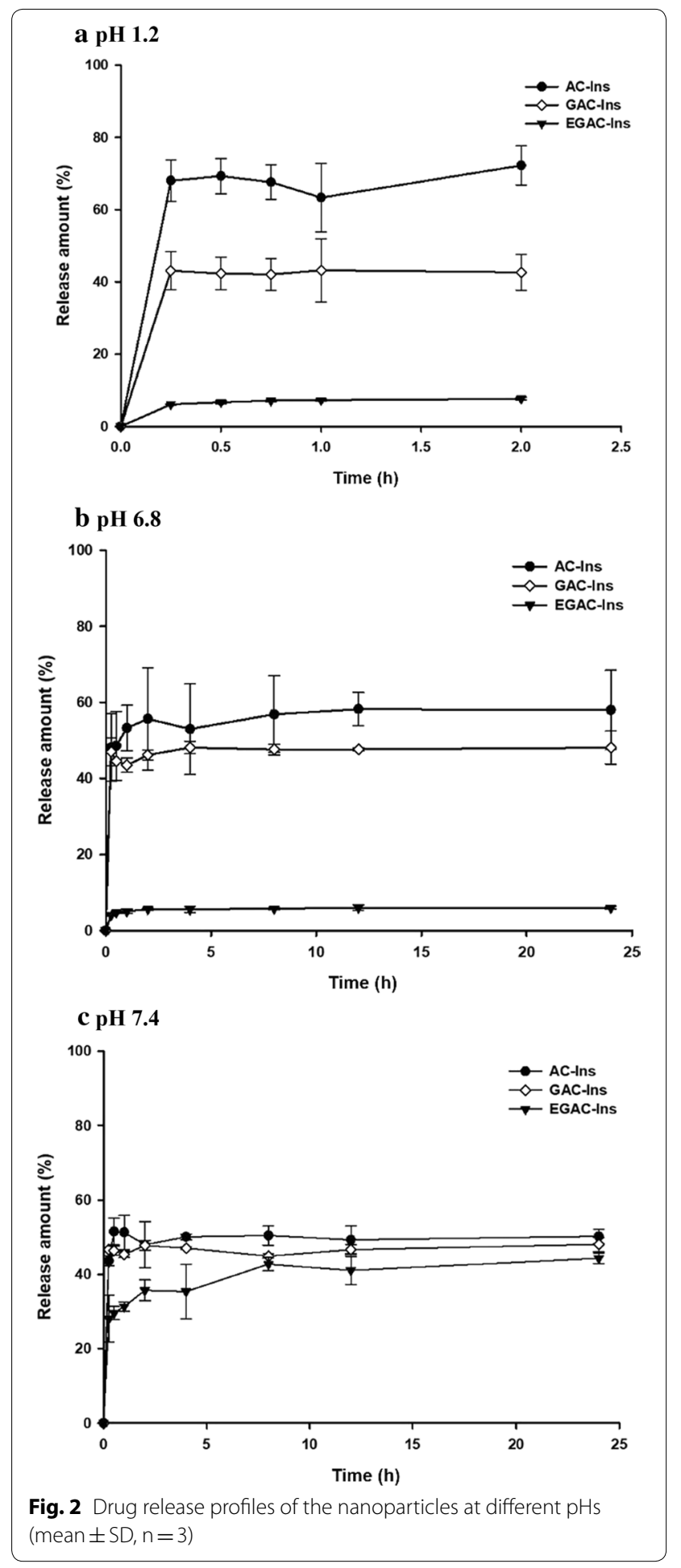

a free insulin solution, all of the nanoparticles increased drug permeability approximately sevenfold (Fig. 5a). This might have occurred, at least in part, because glycolchitosan and aminoclay may facilitate the paracellular
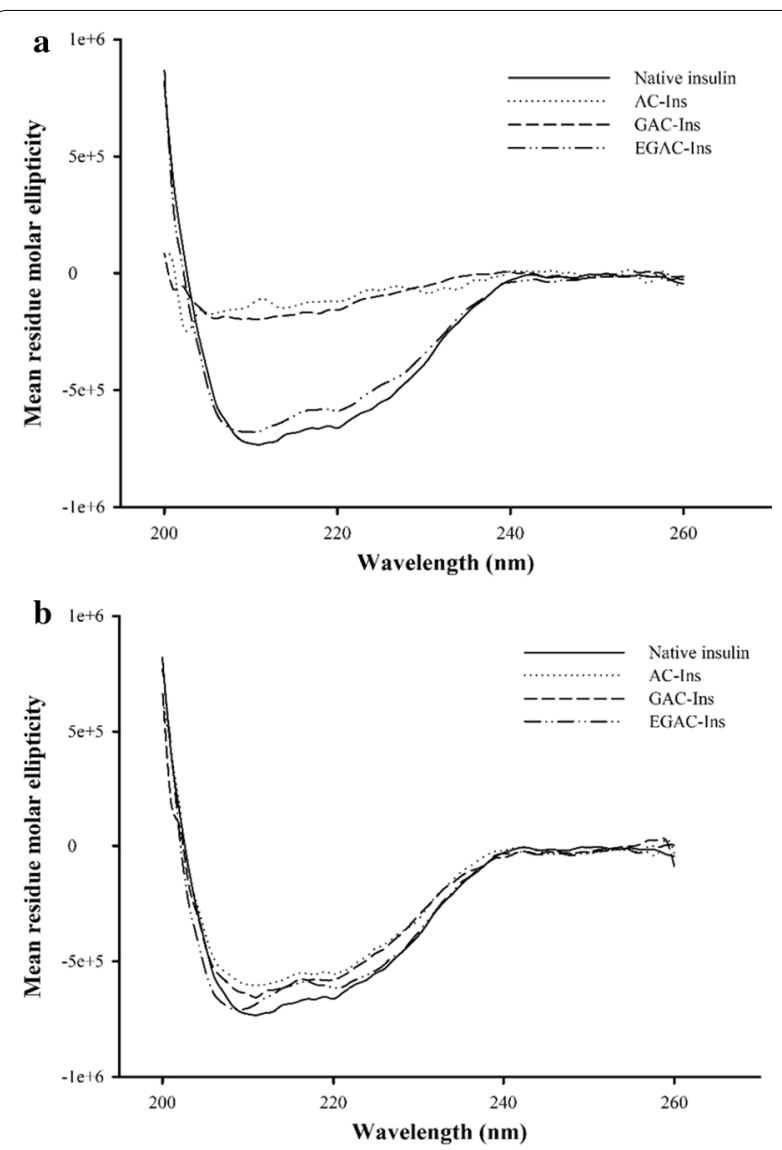

Fig. 3 CD spectra of insulin released from different formulations after incubation in SGF for $1 \mathrm{~h}(\mathbf{a})$ and SIF for $2 \mathrm{~h}$ (b)

transport of nanoparticles via tight junction opening [24, 33]. Therefore, TEER values were measured during incubation in the presence and absence of the nanoparticles. As shown in Fig. 5b, TEER values significantly decreased in the presence of nanoparticles and fully recovered after the nanoparticles were removed. These results suggest that the nanoparticles likely have a reversible and transient effect on tight junction opening and enhance drug permeation.

Taken together, these results suggest that the nanoparticles might be effective at improving insulin transport across the epithelial membrane.

\section{Colonic absorption study in rats}

The effectiveness of EGAC-Ins as a colon-targeted drug delivery system was evaluated by monitoring colonic drug absorption in rats. After oral administration of EGAC-FITC-Ins or a free FITC-Ins solution, the extent of colonic drug permeation was examined with a bioimaging assay. As illustrated in Fig. 6, after oral administration of free FITC-Ins solution, fluorescence signals were negligible in the colonic tissues of rats. This is likely 


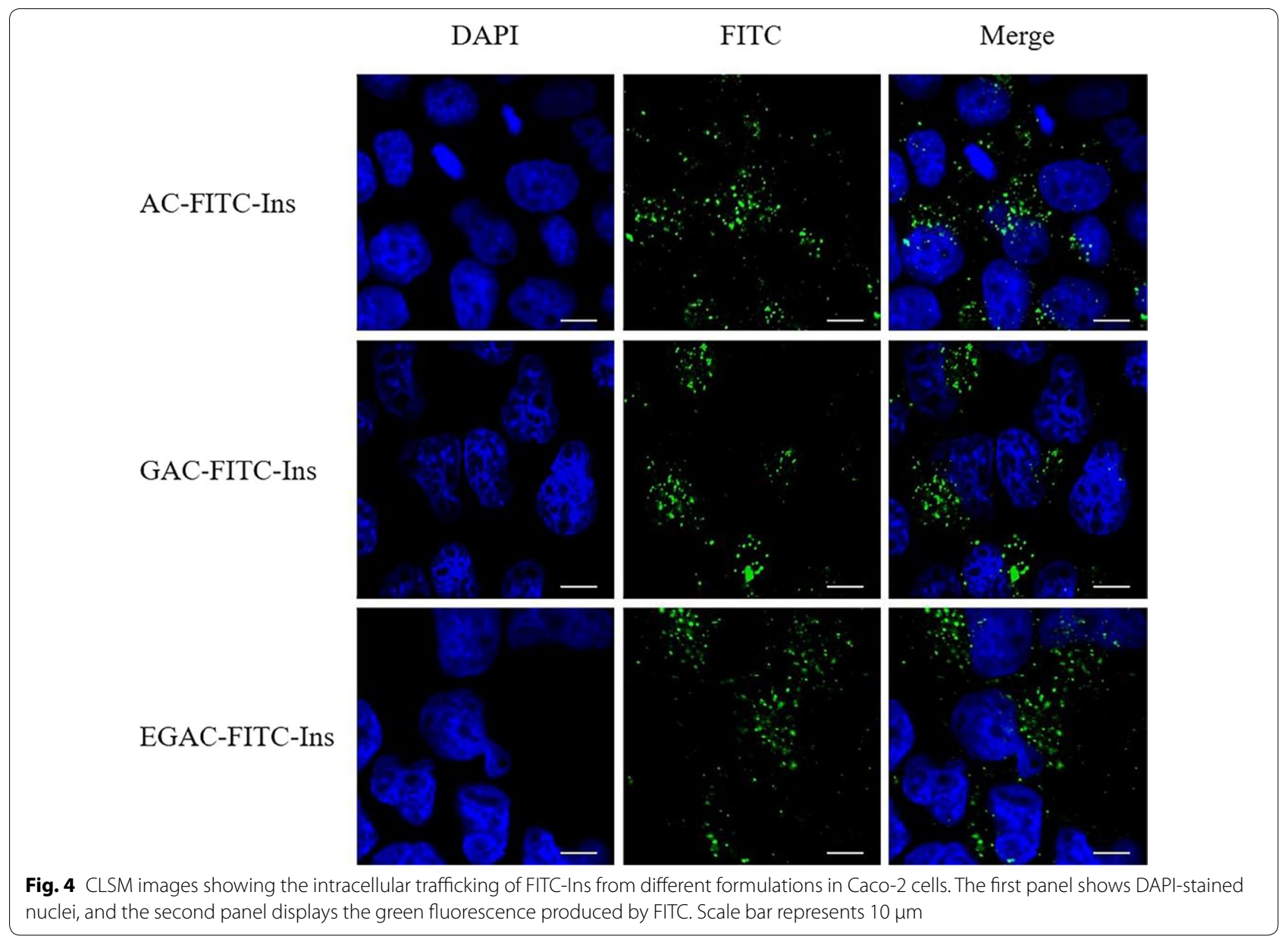

due to the physicochemical and enzymatic instability of insulin in the GI tract before reaching the colon as well as low drug permeability [38]. Alternatively, EGACFITC-Ins achieved significantly higher colonic distribution when compared to the free drug solution. Several factors may explain the enhanced colonic drug distribution via EGAC-FITC-Ins. First, the pH-dependent polymer coating may minimize premature drug release in the upper GI tract and protect the entrapped insulin from acidic and proteolytic degradation. Second, after dissolution of the Eudragit S100 coating layer in the colon, the released cationic nanoparticles might interact with negatively charged colonic mucosa and increase drug residence time in the colon. Third, based on in vitro studies in Caco-2 cells, the nanoparticles may enhance the drug permeation across the epithelial membrane.

Collectively, EGAC-FITC-Ins was more effective at facilitating colonic insulin absorption in rats, when compared to free drug solution.

\section{Hypoglycemic effect in diabetic rats}

The hypoglycemic effect of orally-administered nanoparticles and conventional SC injection was compared in diabetic rats. As summarized in Fig. 7, SC injection of insulin solution rapidly decreased blood glucose concentrations by up to $31.4 \%$ of initial blood glucose levels within $1 \mathrm{~h}$, which was maintained for $1 \mathrm{~h}$ and then gradually recovered to initial blood glucose levels within $6 \mathrm{~h}$ after dosage. In contrast, orally administered insulin solution did not exhibit any hypoglycemic effect, likely due to instability in the GI tract and low membrane permeability. After oral administration of EGAC-Ins, blood glucose levels significantly decreased by up to $38.9 \%$ of initial blood glucose concentrations within $8 \mathrm{~h}$ and then gradually recovered to initial blood glucose levels within $12 \mathrm{~h}$ after dosage. Consistent with the in vitro studies, the improved stability and permeability of insulin delivered via EGAC-Ins nanoparticles significantly enhanced the hypoglycemic effect of orally administered insulin. When compared to SC injection, orally administered EGAC-Ins exhibited a slower and longer duration of action. EGAC-Ins minimized 

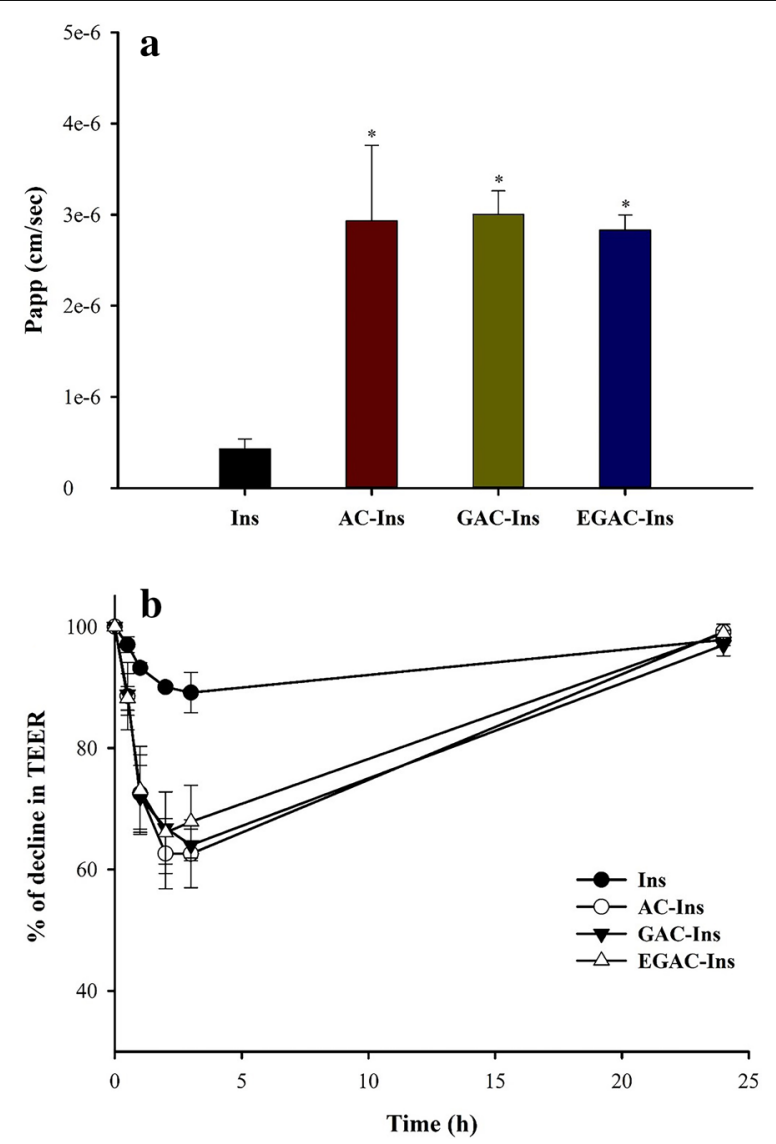

Fig. 5 Cellular transport of insulin with different formulations (a), and the effect of nanoparticles on the trans-epithelial electrical resistance (TEER) (b) in Caco-2 cells (mean $\pm S D, n=3$ ). TEER values were measured during incubation in the presence and absence of nanoparticles. After $4 \mathrm{~h}$ of incubation, the drug solution was replaced by fresh culture medium, and TEER value recovery was monitored over time. ${ }^{*} p<0.05$, compared to free insulin solution

burst drug release in the stomach and upper intestine and slowly released insulin in the lower intestine and colon. Therefore, the onset time of orally administered EGAC-Ins was longer than that from SC injection of insulin solution [39]. However, it lowered blood glucose levels for a longer time period when compared to SC injection.

Collectively, these results suggest that EGAC-Ins is an effective oral delivery system of insulin.

\section{Conclusion}

In this study, a colon-targeted ternary nanocomposite system composed of organoclay/glycol-chitosan/ Eudragit ${ }^{\circledR}$ S100 was developed to enhance the oral delivery of insulin. EGAC-Ins, an insulin-loaded ternary nanocomposite formulation, was obtained as nano-sized particles with high entrapment efficiency
(>90\%). EGAC-Ins displayed pH-dependent drug release characteristics that minimized premature drug release in the upper GI tract. The conformational stability of insulin entrapped in EGAC-Ins was preserved in simulated gastrointestinal fluids. In addition to the enhanced cell permeability and colonic absorption of insulin in rats via EGAC-Ins, orally-administered EGAC-Ins significantly improved the hypoglycemic effect in diabetic rats while the efficacy of oral insulin solution was negligible. Taken together, the present study suggests that EGAC-Ins might be useful to enhance the bioavailability and efficacy of oral insulin.

\section{Methods}

\section{Materials}

Insulin was purchased from FUJIFILM Wako Pure Chemical Co. (Osaka, Japan). Eudragit ${ }^{\circledR} \mathrm{S} 100$ was obtained from Evonik Korea Ltd. (Seoul, Korea). Glycol-chitosan, fluorescein isothiocyanate (FITC)-labeled insulin, formic acid, pepsin, trypsin, and 3-aminopropyltriethoxysilane (APTES, 99\%) were purchased from Sigma-Aldrich Co. (St Louis, MO, USA). Dulbecco's Modified Eagle's medium (DMEM), Hank's balanced salt solution (HBSS), non-essential amino acids, fetal bovine serum (FBS), penicillin-streptomycin, and all other reagents used in cell culture studies were obtained from GE Healthcare Life Sciences (South Logan, UT, USA). 4',6-diamidino-2-phenylindole (DAPI) was purchased from Invitrogen Molecular Probes (Karlsruhe, Germany). Magnesium chloride hexahydrate (98\%) and other inorganic salts were purchased from Junsei Chemical Co., Ltd (Tokyo, Japan). All other chemicals and reagents were HPLC-grade.

Caco-2 cells (human epithelial colorectal adenocarcinoma cells) were purchased from the Korean Cell Line Bank (Seoul, Korea). Cells were grown in DMEM containing $10 \%$ FBS, $1 \%$ nonessential amino acid, and $1 \%$ antibiotics. Cells were incubated at $37{ }^{\circ} \mathrm{C}$ in an atmosphere of $5 \% \mathrm{CO}_{2}$ and $90 \%$ relative humidity.

\section{Preparation of nanoparticles}

First, 3-aminopropyl-functionalized magnesium phyllosilicate (aminoclay) was synthesized by a previously described method [16]. Briefly, magnesium chloride $(8.4 \mathrm{~g})$ was dissolved in ethanol $(200 \mathrm{~mL})$. 3-Aminopropyltriethoxysilane $(13 \mathrm{~mL})$ was then added dropwise under vigorous stirring at $200 \mathrm{rpm}$, which rapidly formed white precipitate that was stirred overnight. The resulting product was separated by centrifugation, washed three times in ethanol, and dried in an oven at $50{ }^{\circ} \mathrm{C}$. Aminoclay was exfoliated by dispersing the bulk powder in water followed by ultra-sonication for $10 \mathrm{~min}$. 


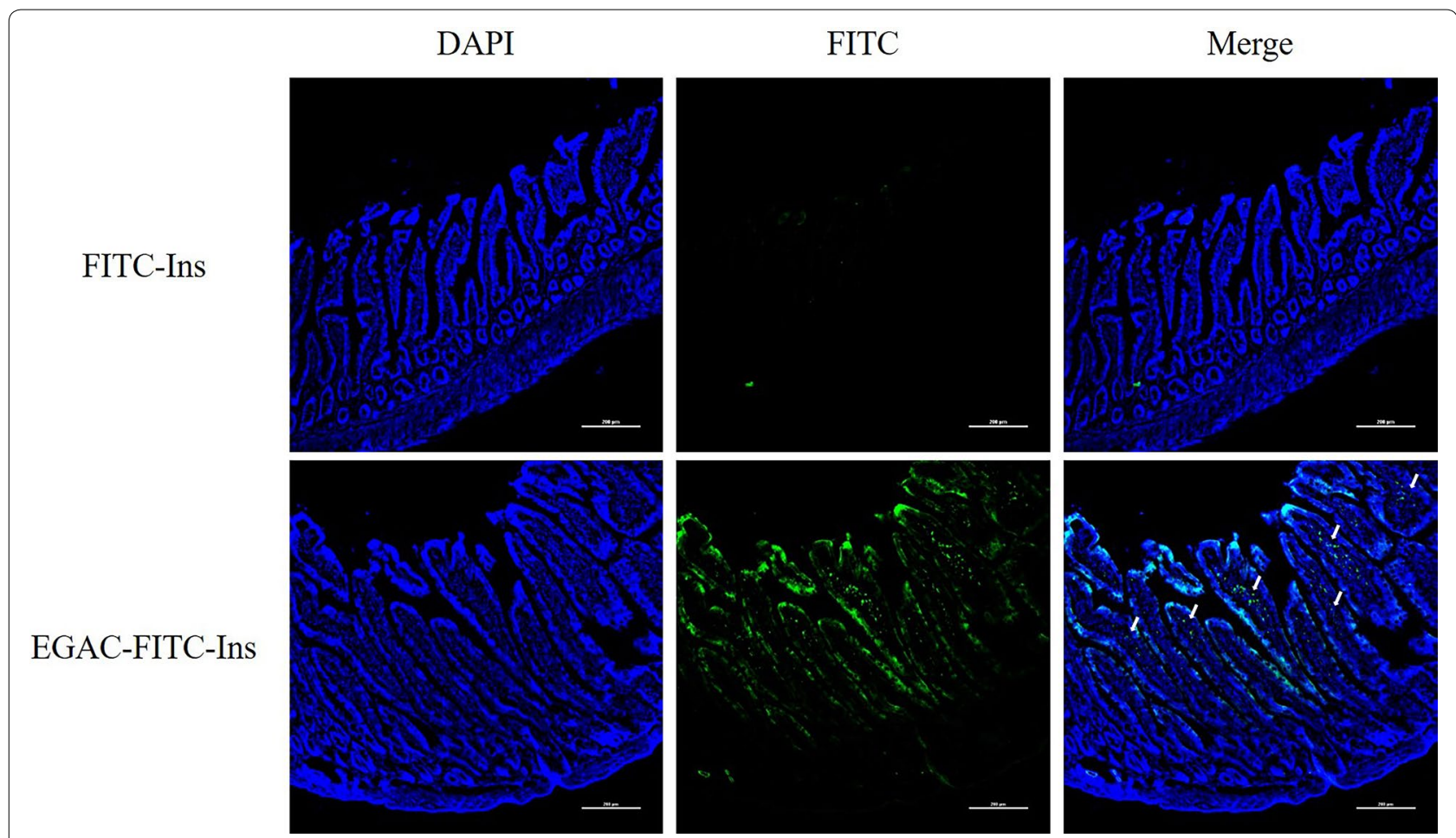

Fig. 6 CLSM images of excised colon after oral administration of FITC-Ins or EGAC-FITC-Ins in rats. Dose was equivalent to 50 IU/kg FITC-Ins, and colonic sections were taken $6 \mathrm{~h}$ after dosage (scale bar represents $200 \mu \mathrm{m}$ )

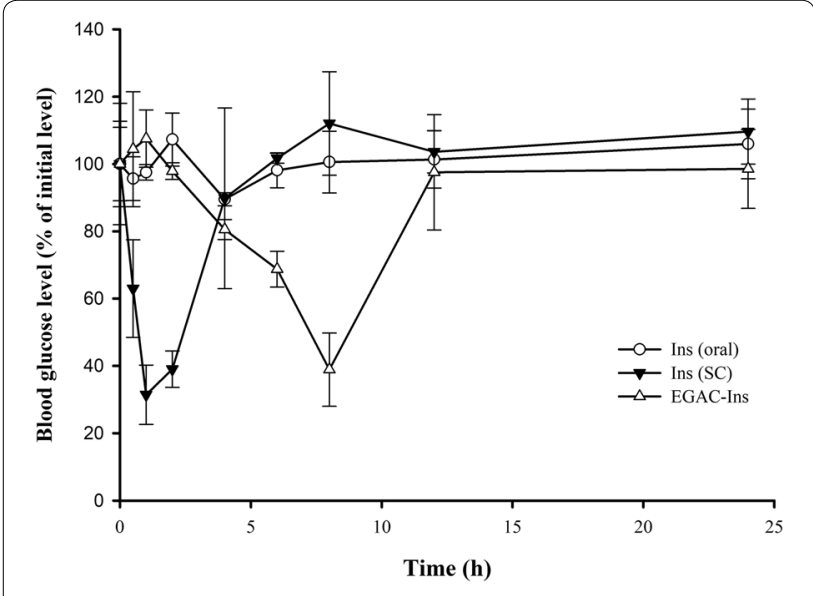

Fig. 7 Hypoglycemic effect after oral or subcutaneous injection of each formulation in diabetic rats (mean $\pm S D, n=3$ )

An insulin-aminoclay nanocomplex (AC-Ins) was prepared by electrostatic interactions between aminoclay and insulin. Briefly, insulin $(10 \mathrm{mg})$ was dissolved in $10 \mathrm{mM} \mathrm{HCl}(1 \mathrm{~mL})$, and $100 \mathrm{mM}$ Tris $-\mathrm{HCl}$ was added at a ratio of 1:1 (v/v). This insulin solution $(5 \mathrm{mg} /$ $\mathrm{mL}$ ) was added dropwise into an aqueous suspension of aminoclay $(10 \mathrm{mg} / \mathrm{mL})$ at a drug/clay ratio of $1: 3$ at room temperature. After stirring for $4 \mathrm{~h}$, the generated AC-Ins was separated by centrifugation $(22,250 g)$ at $4{ }^{\circ} \mathrm{C}$ for $10 \mathrm{~min}$ and air-dried at room temperature. The aqueous suspension of AC-Ins $(3 \mathrm{mg} / \mathrm{mL})$ was added dropwise into an equal volume of a $0.2 \%$ glycolchitosan solution at $\mathrm{pH} 5.5$ while stirring at $300 \mathrm{rpm}$ for $30 \mathrm{~min}$. The resultant nanoparticles (GAC-Ins) were collected by ultra-centrifugation $(77,100 g)$ at $4{ }^{\circ} \mathrm{C}$ for $15 \mathrm{~min}$. After re-dispersion of GAC-Ins in distilled water, the GAC-Ins aqueous suspension $(3 \mathrm{mg} / \mathrm{mL})$ was added into an equal volume of $0.2 \%$ Eudragit $^{\circledR}$ S100 dissolved in ethanol while stirring at $300 \mathrm{rpm}$ for $30 \mathrm{~min}$. After ultra-centrifugation $(77,100 \mathrm{~g})$ at $4{ }^{\circ} \mathrm{C}$ for $15 \mathrm{~min}$, the collected nanoparticles (EGAC-Ins) were air-dried at room temperature.

For the bioimaging study, FITC-insulin-loaded nanoparticles were also prepared using the same procedure described above; however, insulin was replaced by fluorescent FITC-insulin.

\section{Structural characterization of the nanoparticles}

The particle size and zeta potential of all insulin-loaded nanoparticles were measured by dynamic light scattering (DLS) using a Zetasizer Nano-ZS90 (Malvern Instruments, Malvern, UK). The polydispersity index (PDI) was 
also measured as a dimensionless number indicating the size distribution. The entrapment efficiency (EE) of each nanoparticle was calculated by the following equation:
SIF. The nanoparticles were collected by centrifugation at 22,250 $\mathrm{g}$ for $10 \mathrm{~min}$, and insulin in the nanoparticles was extracted in phosphate buffer ( $\mathrm{pH}$ 7.4) for $2 \mathrm{~h}$. The con-

$$
\mathrm{EE}(\%)=\frac{\text { Amount of drug initially added }- \text { Amount of drug in supernatant }}{\text { Amount of drug initially added }} \times 100
$$

The structural characterization of all nanoparticles was also performed using Fourier transform infrared spectroscopy (FT-IR) (Nicolet ${ }^{\mathrm{TM}}$ iS $^{\mathrm{TM}} 5$; Thermo Fisher Scientific, Waltham, MA, USA) with a ZnSe crystal accessory. The FT-IR spectrum of each sample was measured over a wavenumber range of $4000-500 \mathrm{~cm}^{-1}$ with 64 scans at resolution of $4 \mathrm{~cm}^{-1}$.

Circular dichroism (CD) analysis was used to examine the structural stability of insulin released from the nanoparticles. Far UV CD spectra were collected using the Chirascan ${ }^{\mathrm{TM}}$-Plus Spectrometer (Applied Photophysics, Surrey, UK). Wavelength spectra were collected from $200 \mathrm{~nm}$ to $260 \mathrm{~nm}$ at $25^{\circ} \mathrm{C}$ with a bandwidth of $1 \mathrm{~nm}$ and a light path length of $0.5 \mathrm{~mm}$.

The morphological characteristics of the nanoparticles were monitored by transmission electron microscopy (TEM) (JEM-F200; JEOL Ltd., Tokyo, Japan). The compositional elements of the developed formulations were analyzed by energy-dispersive X-ray spectroscopy (EDX). TEM and EDX analyses were performed at the National Center for Inter-University Research Facilities (NCIRF) at Seoul National University (Seoul, Korea).

\section{In vitro drug release studies}

The drug release profiles of the nanoparticles were evaluated at pHs 1.2, 6.8, and 7.4. Nanoparticles (equivalent to $0.2 \mathrm{mg} / \mathrm{mL}$ insulin) were dispersed in release medium, while shaking at $100 \mathrm{rpm}$ at $37^{\circ} \mathrm{C}$. At predetermined time points, samples were collected and centrifuged at 22,250g for $10 \mathrm{~min}$. The supernatants were analyzed by HPLC to determine the amount of drug released. $\mathrm{CD}$ analysis was also used to detect the molecular conformation of insulin released from the nanoparticles.

\section{Protection against enzymatic degradation}

To examine the protective effect of the nanoparticles against proteolytic degradation, the structural stability of insulin entrapped in the nanoparticles was evaluated in simulated gastric juice (SGF, pH 1.2 with $5 \mu \mathrm{g} / \mathrm{mL}$ pepsin) and intestinal fluid (SIF, pH 7.4 with $50 \mu \mathrm{g} / \mathrm{mL}$ trypsin) as reported by Rekha and Sharma [40] with slight modifications. An aliquot of nanoparticles was incubated in SGF $(1 \mathrm{~mL})$ or $\operatorname{SIF}(1 \mathrm{~mL})$ at $37^{\circ} \mathrm{C}$. At designated time points, the enzymatic reaction was terminated by the addition of either $0.2 \mathrm{~mL}$ of $0.2 \mathrm{M} \mathrm{NaOH}$ into SGF or $0.1 \mathrm{M} \mathrm{HCl}$ into formational stability of insulin extracted from the nanoparticles was examined by $\mathrm{CD}$ analysis.

\section{Confocal laser scanning microscopy (CLSM)}

The intracellular localization of the nanoparticles was examined by confocal laser scanning microscopy (CLSM). Briefly, cells were seeded on slides in 24-well plates at a density of $5 \times 10^{4}$ cells per well and incubated for $24 \mathrm{~h}$. After removing the medium, the cells were washed three times with PBS. Each formulation (FITCIns, AC-FITC-Ins, GAC-FITC-Ins, or EGAC-FITC-Ins) in HBSS was added to the cells at a concentration equivalent to $25 \mu \mathrm{g} / \mathrm{mL}$ FITC-Ins and incubated at $37^{\circ} \mathrm{C}$. After incubating for $3 \mathrm{~h}$, the cells were washed three times with PBS and fixed in 4\% paraformaldehyde for $15 \mathrm{~min}$. The nuclei were stained with DAPI for 3 min at room temperature. The intracellular distribution of nanoparticles was visualized using a Nikon C1 CLSM with EZ-C1 software (Nikon, Tokyo, Japan).

\section{Trans-epithelial transport studies}

Caco- 2 cells were seeded at a density of $2.0 \times 10^{5}$ cells/ well on trans-well plates with a surface area of $1.12 \mathrm{~cm}^{2}$. The cells were incubated at $37^{\circ} \mathrm{C}$ for 21 days, and the medium was refreshed regularly. The integrity of cell monolayers was monitored by measuring trans-epithelial electrical resistance (TEER) using an epithelial tissue voltohmmeter (Millicell ERS-2, Merck KGaA, Darmstadt, Germany).

Prior to the transport studies, the medium was replaced with $\mathrm{HBSS}$ and incubated at $37{ }^{\circ} \mathrm{C}$ for $30 \mathrm{~min}$. Then, HBSS on the apical side was replaced by a drug solution containing each formulation equivalent to $10 \mu \mathrm{g} / \mathrm{mL}$ insulin. At predetermined time points, samples were collected from the basolateral compartment and replenished with an equal volume of fresh HBSS to maintain a constant volume. Drug concentrations were determined using an LC-MS/MS. The apparent permeability coefficient $\left(\mathrm{P}_{\text {app }}\right)$ was calculated using the following equation: $P_{\text {app }}=d Q / d t \times 1 / A_{0}$, where $d Q / d t$ is the cumulative drug amount in the basolateral compartment as a function of time, $\mathrm{A}$ is the surface area of membrane filter, and $\mathrm{C}_{0}$ is the initial drug concentration in the apical compartment. 


\section{Ex vivo permeation studies in rats}

Animal studies were conducted in accordance with the "Guiding Principles in the Use of Animals in Toxicology" adopted by the Society of Toxicology (USA), and the study protocol was approved by the review committee of Dongguk University (IACUC-2017-016-4). Male Sprague-Dawley rats (150-170 g) were obtained from Orient Bio Inc. (Seongnam, Korea). Rats were fasted for $12 \mathrm{~h}$ before the experiment but were given free access to tap water. An aqueous suspension of EGAC-FITC-Ins or FITC-Ins was administered to the rats by oral gavage at a dose equivalent of $50 \mathrm{IU} / \mathrm{kg}$ FITC-Ins. Rats were sacrificed $6 \mathrm{~h}$ after dosage, and colons were excised immediately after laparotomy. The colons were washed with PBS to remove the luminal content. The colon tissues were fixed with $4 \%$ paraformaldehyde for 1 day and placed in $30 \%$ sucrose solution until the tissues sank. Next, the colon tissues were cryo-sectioned and examined by confocal microscopy (Nikon C1, Nikon, Tokyo, Japan) to visualize the localization of FITC-Ins.

\section{Hypoglycemic effect in diabetic rats}

Male Wistar rats $(150 \pm 20 \mathrm{~g})$ were supplied by Orient Bio Inc. (Seongnam, Korea). The study protocol was approved by the review committee of Dongguk University (IACUC-2017-016-4). Rats were fasted for $12 \mathrm{~h}$ before the experiment but were allowed water ad libitum. Diabetes was induced by an intraperitoneal injection of streptozotocin (STZ in $0.05 \mathrm{~mol} / \mathrm{L}$ citrate buffer solution, $\mathrm{pH} 4.5)$ at a dose of $65 \mathrm{mg} / \mathrm{kg}$. After 4 days, blood was collected from tail veins, and blood glucose levels were measured with a Roche glucose meter (ACCU-CHEK ${ }^{\circledR}$ guide). Rats with a fasting blood glucose over $250 \mathrm{mg} / \mathrm{dL}$ were used as diabetic rat models [41].

Twelve STZ-induced diabetic rats were randomly divided into 3 groups. All rats were fasted for $6 \mathrm{~h}$ before the experiment but were allowed water ad libitum. Group 1 was administered an insulin solution $(5 \mathrm{IU} / \mathrm{kg}$ ) via SC injection. Groups 2 and 3 were administered an insulin solution or EGAC-Ins, respectively, at the dose equivalent of $100 \mathrm{IU} / \mathrm{kg}$ of insulin via oral gavage. At predetermined time points, blood samples were collected from tail veins to measure blood glucose levels. Blood glucose levels were measured using a Roche glucose meter (ACCU-CHEK ${ }^{\circledR}$ guide) and were expressed as a percentage of the initial glucose levels [9].

\section{Analytical assays}

Drug concentrations were determined by HPLC and LC-MS/MS. The HPLC system (Flexar; Perkin Elmer,
MA, USA) consisted of an automatic injector, a UV detector and two solvent delivery pumps. Samples were injected into the HPLC system connected to a column (Gemini C18, $4.6 \times 150 \mathrm{~mm}, 5 \mu \mathrm{m}$; Phenomenex, Torrance, CA, USA). Chromatographic separation was achieved by eluting the mobile phase (acetonitrile: $0.1 \%$ trifluoroacetic acid $=30: 70, \mathrm{v} / \mathrm{v}$ ) at a flow rate of $1 \mathrm{~mL} /$ min with a column temperature of $30{ }^{\circ} \mathrm{C}$. Prednisone was used as an internal standard. The detection wavelength was set to $215 \mathrm{~nm}$. The calibration curve was obtained in the range of $10-500 \mu \mathrm{g} / \mathrm{mL}$ with good linearity $\left(R^{2}>0.9996\right)$.

For LC-MS/MS analysis, the chromatographic separation of analytes was performed with a $\mathrm{C} 18$ column $(4.6 \times 100 \mathrm{~mm}, 2.6 \mu \mathrm{m}$; Phenomenex, Torrance, CA, USA) at $30{ }^{\circ} \mathrm{C}$. The mobile phase consisted of acetonitrile with $0.1 \%$ formic acid and water with $0.1 \%$ formic acid $(60: 40, \mathrm{v} / \mathrm{v})$, and the flow rate was $1 \mathrm{~mL} / \mathrm{min}$. Mass spectrometric detection was achieved using positive ion electrospray ionization in multiple-reaction monitoring (MRM) mode by an ABSciex API 4000 triple quadrupole mass spectrometer (ABSciex, Framingham, MA, USA). The precursor/product ion pair $(\mathrm{m} / \mathrm{z})$ was $1162.6 / 143.2$ for the drug and 271.2/155.1 for the internal standard (tolbutamide). The calibration curve was obtained in the range of $20-1000 \mathrm{ng} / \mathrm{mL}$ with good linearity $\left(\mathrm{R}^{2}>9996\right)$.

\section{Statistical analyses}

All data are expressed as the mean \pm standard deviation (SD). Statistical analyses were performed using one-way ANOVA followed by Dunnett's test. Values of $p<0.05$ were considered significant.

\section{Acknowledgements}

Not applicable.

\section{Authors' contributions}

SHL, SYB, and JGS performed experiments and analyzed the data. HK Han designed experiments, gave the intellectual input and edited the manuscript. All authors read and approved the final manuscript.

\section{Funding}

This research was supported by the National Research Foundation of Korea (NRF) grant funded by the Korea government (MSIT) (No. 2019R1A2C2004873 and 2018R1A5A2023127).

\section{Ethics approval and consent to participate}

All animal studies were approved by the review committee of Dongguk University (IACUC-2017-016-4).

\section{Consent for publication}

Not applicable.

Competing interests

All authors declare that they have no conflicts of interest.

Received: 27 April 2020 Accepted: 13 July 2020

Published online: 25 July 2020 


\section{References}

1. Sauna ZE, Lagassé HAD, Alexaki A, Simhadri VL, Katagiri NH, Jankowski $W$, et al. Recent advances in (therapeutic protein) drug development. F1000Research. 2017;6:113

2. Bruno BJ, Miller GD, Lim CS. Basics and recent advances in peptide and protein drug delivery. Ther Deliv. 2013;4:1443-67.

3. Aungst BJ, Saitoh H, Burcham DL, Huang SM, Mousa SA, Hussain MA Enhancement of the intestinal absorption of peptides and non-peptides. J Control Release. 1996;41:19-31.

4. Wong CY, Al-Salami H, Dass CR. Potential of insulin nanoparticle formulations for oral delivery and diabetes treatment. J Control Release. 2017:264:247-75.

5. Han D-G, Cho S-S, Kwak J-H, Yoon I-S. Medicinal plants and phytochemicals for diabetes mellitus: pharmacokinetic characteristics and herb-drug interactions. J Pharm Investig. 2019;49:603-12.

6. Concannon P, Rich SS, Nepom GT. Genetics of type 1A diabetes. N Engl J Med. 2009;360:1646-54

7. Hamaty M. Insulin treatment for type 2 diabetes: when to start, which to use. Cleve Clin J Med. 2011;78:332-42.

8. Im G-B, Bhang $\mathrm{SH}$. Recent research trend in cell and drug delivery system for type 1 diabetes treatment. J Pharm Investig. 2018;48:175-85.

9. Chen S, Guo F, Deng T, Zhu S, Liu W, Zhong H, et al. Eudragit S100coated chitosan nanoparticles co-loading Tat for enhanced oral colon absorption of insulin. AAPS Pharm Sci Tech. 2017;18:1277-87.

10. Ensign LM, Cone R, Hanes J. Oral drug delivery with polymeric nanoparticles: the gastrointestinal mucus barriers. Adv Drug Deliv Rev. 2012;64:557-70.

11. Ghosh D, Peng X, Leal J, Mohanty RP. Peptides as drug delivery vehicles across biological barriers. J Pharm Investig. 2018:48:89-111.

12. Kim Y-C, Min KA, Jang D-J, Ahn TY, Min JH, Yu BE, et al. Practical approaches on the long-acting injections. J Pharm Investig. 2020:50:147-57.

13. Kshirsagar SJ, Bhalekar MR, Umap RR. In vitro in vivo comparison of two pH sensitive Eudragit polymers for colon specific drug delivery. J Pharm Sci Res. 2009;1:67-70.

14. Sinha VR, Singh A, Kumar RV, Singh S, Kumria R, Bhinge JR. Oral colon-specific drug delivery of protein and peptide drugs. Crit Rev Ther Drug Carrier Syst. 2007:24:63-92.

15. Maroni A, Zema L, Del Curto MD, Foppoli A, Gazzaniga A. Oral colon delivery of insulin with the aid of functional adjuvants. Adv Drug Deliv Rev. 2012;24:540-56

16. Yang L, Choi SK, Shin HJ, Han HK. 3-aminopropyl functionalized magnesium phyllosilicate as an organoclay based drug carrier for improving the bioavailability of flurbiprofen. Int J Nanomed. 2013;8:4147-55.

17. Datta KKR, Achari A, Eswaramoorthy M. Aminoclay: a functional layered material with multifaceted applications. J Mater Chem A. 2013;1:6707-18.

18. Song JG, Lee SH, Han HK. Biophysical evaluation of aminoclay as an effective protectant for protein stabilization during freeze-drying and storage. Int J Nanomed. 2016:11:6609-19.

19. Kubota N, Ohga K, Moriguchi M. Permeability properties of glycol chitosan membrane modified with thiol groups. J Appl Polym Sci. 1991:42:495-501.

20. Kwon S, Park JH, Chung H, Kwon IC, Jeong SY, Kim IS. Physicochemical characteristics of self-assembled nanoparticles based on glycol chitosan bearing 5ß-cholanic acid. Langmuir. 2003;19:10188-93.

21. Yu JM, Li YJ, Qiu LY, Jin Y. Self-aggregated nanoparticles of cholesterolmodified glycol chitosan conjugate: preparation, characterization, and preliminary assessment as a new drug delivery carrier. Eur Polym J. 2008:44:555-65.

22. Lee ES, Park KH, Park IS, Na K. Glycol chitosan as a stabilizer for protein encapsulated into poly(lactide-co-glycolide) microparticle. Int J Pharm. 2007;338:310-6.

23. Palazzo C, Trapani G, Ponchel G, Trapani A, Vauthier C. Mucoadhesive properties of low molecular weight chitosan- or glycol chitosan- and corresponding thiomer-coated poly(isobutylcyanoacrylate) core-shell nanoparticles. Eur J Pharm Biopharm. 2017;117:315-23.

24. Lee SH, Song JG, Han HK. Development of pH-responsive organicinorganic hybrid nanocomposites as an effective oral delivery system of protein drugs. J Control Release. 2019;311-312:74-84.

25. Ali Asghar LF, Chandran S. Multiparticulate formulation approach to colon specific drug delivery: current perspectives. J Pharm Pharm Sci. 2006:9:327-38
26. Makhlof A, Tozuka Y, Takeuchi H. pH-sensitive nanospheres for colon-specific drug delivery in experimentally induced colitis rat model. Eur J Pharm Biopharm. 2009;72:1-8.

27. Wang XQ, Zhang Q. $\mathrm{pH}$-sensitive polymeric nanoparticles to improve oral bioavailability of peptide/protein drugs and poorly water-soluble drugs. Eur J Pharm Biopharm. 2012;82:219-29.

28. Azevedo JR, Sizilio RH, Brito MB, Costa AMB, Serafini MR, Araújo AAS, et al. Physical and chemical characterization insulin-loaded chitosan-TPP nanoparticles. J Therm Anal Calorim. 2011;106:685-9.

29. Manning MC, Chou DK, Murphy BM, Payne RW, Katayama DS. Stability of protein pharmaceuticals: an update. Pharm Res. 2010;27:544-75.

30. Zhou H, Qian H. Preparation and characterization of $\mathrm{pH}$-sensitive nanoparticles of budesonide for the treatment of ulcerative colitis. Drug Des Devel Ther. 2018;12:2601-9.

31. Sarkar A, Goh KKT, Singh RP, Singh H. Behaviour of an oil-in-water emulsion stabilized by $\beta$-lactoglobulin in an in vitro gastric model. Food Hydrocoll. 2009;23:1563-9.

32. Hernández-Ledesma B, Del Mar Contreras M, Recio I. Antihypertensive peptides: production, bioavailability and incorporation into foods. Adv Colloid Interface Sci. 2011;165:23-35.

33. Feng J, Chen Y, Li F, Cui L, Shi N, Kong W, et al. Synthesis, characterization and in vitro evaluation of a novel glycol chitosan-EDTA conjugate to inhibit aminopeptidase-mediated degradation of thymopoietin oligopeptides. Molecules. 2017;22:e1253

34. Park JS, Cho YW. In vitro cellular uptake and cytotoxicity of paclitaxelloaded glycol chitosan self-assembled nanoparticles. Macromol Res. 2007;15:513-9.

35. Trapani A, Sitterberg J, Bakowsky U, Kissel T. The potential of glycol chitosan nanoparticles as carrier for low water soluble drugs. Int J Pharm. 2009;375:97-106.

36. Nam HY, Kwon SM, Chung H, Lee SY, Kwon SH, Jeon H, et al. Cellular uptake mechanism and intracellular fate of hydrophobically modified glycol chitosan nanoparticles. J Control Release. 2009;145:259-67.

37. Yan L, Crayton SH, Thawani JP, Amirshaghaghi A, Tsourkas A, Cheng Z. A pH-responsive drug-delivery platform based on glycol chitosan-coated liposomes. Small. 2015;11:4870-4.

38. El Leithy ES, Abdel-Bar HM, Ali RAM. Folate-chitosan nanoparticles triggered insulin cellular uptake and improved in vivo hypoglycemic activity. Int J Pharm. 2019;571:118708.

39. Kararli TT. Comparison of the gastrointestinal anatomy, physiology, and biochemistry of humans and commonly used laboratory animals. Biopharm Drug Dispos. 1995:16:351-80.

40. Rekha MR, Sharma CP. Synthesis and evaluation of lauryl succinyl chitosan particles towards oral insulin delivery and absorption. J Control Release. 2009;135:144-51.

41. Luippold G, Bedenik J, Voigt A. Short- and longterm glycemic control of streptozotocin-induced diabetic rats using different insulin preparations. PLOS ONE. 2016;11:e0156346.

\section{Publisher's Note}

Springer Nature remains neutral with regard to jurisdictional claims in published maps and institutional affiliations.

Ready to submit your research? Choose BMC and benefit from:

- fast, convenient online submission

- thorough peer review by experienced researchers in your field

- rapid publication on acceptance

- support for research data, including large and complex data types

- gold Open Access which fosters wider collaboration and increased citations

- maximum visibility for your research: over 100M website views per year

At BMC, research is always in progress.

Learn more biomedcentral.com/submissions 